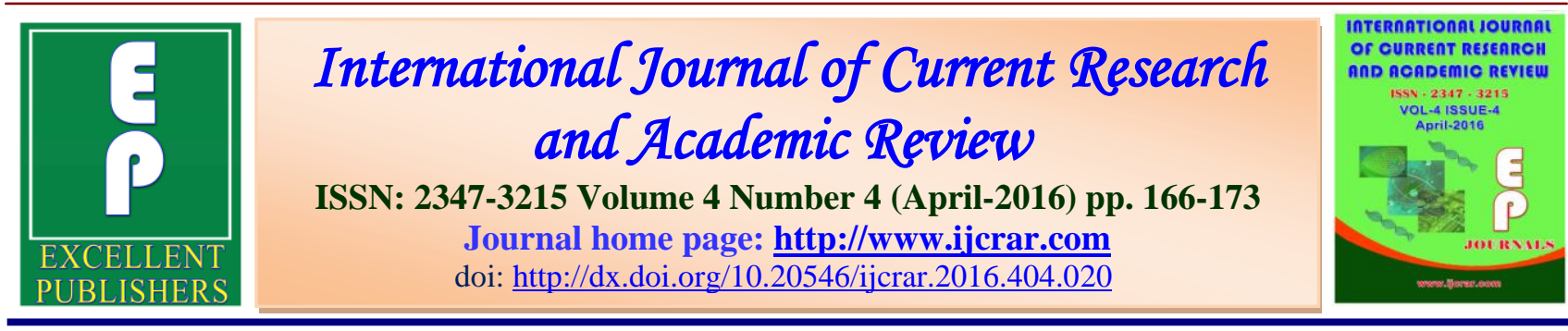

\title{
Psychological Distress and Risk of Anxiety among Women Availing Antenatal Services at a Hospital in Rural South India
}

\author{
Avita Rose Johnson, Sineesh P Joy*, Niresh C, Rajitha K, Nishma Monteiro, Linju \\ Varghese, Vinoliya Sudha and Twinkle Agrawal
}

Department of Community Medicine, St. John's Medical College, Bangalore, India

*Corresponding author

\begin{tabular}{|c|c|}
\hline KEYWORDS & A B S T R A C T \\
\hline $\begin{array}{l}\text { Psychological } \\
\text { distress, } \\
\text { antenatal } \\
\text { anxiety, } \\
\text { rural India, } \\
\text { K10, } \\
\text { PASS-31. }\end{array}$ & $\begin{array}{l}\text { Antenatal anxiety and depression have been known to be associated with poor } \\
\text { maternal and fetal outcomes. There is paucity of data from rural areas of India } \\
\text { on these factors and their outcomes. Hence we conducted a study to estimate } \\
\text { the prevalence of psychological stress and high risk for anxiety among } \\
\text { pregnant women in a hospital in rural South India, and to determine the } \\
\text { association with various socio-demographic and obstetric variables of } \\
\text { importance in the rural Indian context. This was a cross-sectional study } \\
\text { conducted among antenatal women using the Kessler Psychological Distress } \\
\text { Scale (K10) scale and Perinatal Anxiety Screening Scale (PASS). Women } \\
\text { with a score of K10 } \geq 16 \text { were considered to have psychological distress and } \\
\text { PASS score of } \geq 26 \text { were considered as high risk for anxiety. The prevalence } \\
\text { of Psychological Stress (K10 } \geq 16 \text { ) among the } 209 \text { antenatal women in this } \\
\text { study was estimated to be } 29.7 \% \text {, with prevalence rate being significantly } \\
\text { higher in the second trimester as compared to the third trimester. } 64 \text { (30.6\%) } \\
\text { women had high risk for anxiety Consumption of alcohol by the husband and } \\
\text { fewer years of education in husband were found to significantly increase the } \\
\text { risk of anxiety or psychological distress among antenatal women. There was a } \\
\text { significantly positive correlation between K10 and PASS scores with a } \\
\text { correlation coefficient of } 0.654 \text { (p=0.0001). With nearly a third of antenatal } \\
\text { women in the study suffering from psychological distress and a high risk of } \\
\text { anxiety, there is definite evidence for including screening for psychological } \\
\text { distress and anxiety during routine antenatal visits. }\end{array}$ \\
\hline
\end{tabular}

\section{Introduction}

Pregnancy is meant to be a time of joy and fulfillment in a woman's life. However, evidences indicate that there is a higher incidence of psychiatric morbidity, particularly depression and anxiety, during this period (Fatoye F.O. et al., 2004) Many women experience physiological, psychological and social changes, and 
struggle to adapt to these changes during pregnancy (Teixeira C. et al., 2009). The association between postnatal maternal psychological depression and various aspects of child development has been well established (Rahman A. et al., 2004; Patel V. et al., 2004; Stewart R.C. et al., 2007; Field T. et al., 2006; Nulman I. et al., 2002). There is research to support that unidentified and untreated depression and anxiety during the antenatal period can lead to detrimental effects for the mother and the child.

Psychological distress is largely defined as a state of emotional suffering characterized by symptoms of depression (e.g., lost interest; sadness; hopelessness) and anxiety (e.g., restlessness; feeling tense)(Mirowsky and Ross, 2002). A woman with psychological distress is likely to be suffering from depression or anxiety. Depressed women are more likely to have unhealthy practices during pregnancy and higher rates of poor nutrition, in part due to a lack of appetite, leading to poor weight gain during pregnancy and affecting intrauterine growth (Benute G.R. et al., 2010; Marcus S.M. et al., 2009).

Antepartum depressive and anxiety symptoms can also lead to low birth weight, pre-eclampsia (Glover V. et al., 2002), postpartum depression (Gulseren L. et al., 2006; Heron J. et al., 2004), premature delivery (Field T. et al., 2006), negative impact on child development (Austin M.P. et al., 2005; Huizink A.C. et al., 2004) and depression in adolescence (Srinath S. et al., 2005).

However most of the research in antenatal anxiety and psychological stress during pregnancy has been done in developed countries. A few studies have been done in urban India, but considering the high birth rate and large antenatal population of rural India research in this group is important.
The aim of this study was to estimate the prevalence rate of psychological stress and high risk for anxiety in a group of pregnant women in rural south India, and to determine the association with various socio-demographic and obstetric variables of importance in the rural Indian context.

\section{Methods}

This study was carried out at a charitable hospital run by missionaries, located in a village in Magadi Taluk, Ramanagara district, Karnataka. This study was an observational, cross-sectional study carried out in a primary health care setting. Pregnant women above 18 years of age, attending the antenatal clinic at hospital were invited to participate in the study. Women with known history of severe psychiatric morbidity namely schizophrenia or frank psychosis were excluded.

Women who consented to participate in the study were administered two sets of screening questionnaires- Kessler Psychological Distress Scale (K10) scale and Perinatal Anxiety Screening Scale (PASS). Socio-demographic and obstetric data was also collected from the participants.

The Kessler Psychological Distress Scale (K10)scale is a screening measure of general psychological distress containing 10 items. Scores range from 0 to 40 and are based on a recall period of 4 weeks. The Kessler 10 (K10) was developed in 1992 by Professors Kessler and Mroczek for use in the United States National Health Interview Survey as a brief measure of non-specific psychological distress in the anxiety-depression spectrum. The K10 is designed to quantify the frequency and severity of anxiety- and depression-related symptoms experienced in the four weeks prior to screening. The K10 
is a simple measure of psychological distress without identifying its cause. It is a screening instrument to identify people in need of further assessment for anxiety and depression (Kessler, R.C et al., 2003). Reliability tests were done on the K10 scale by E Dal Grande et al., and the values of the kappa and weighted kappa scores ranged from 0.42 to 0.74 which indicated that K10 is a reliable instrument (Kessler R.C. 2004; Grande E. et al., 2002).

Women with a K10 score of $\geq 16$ were considered to have Psychological Distress (K10 Symptom Scale. Clinical Research Unit for Anxiety and Depression.).

Perinatal Anxiety Screening Scale (PASS) is a31-item questionnaire, designed to screen for anxiety in antenatal and postpartum women. The optimal cut off is $\geq 26$ at which the sensitivity is $70 \%$ and specificity is $65 \%$ (Somerville. S et al., 2014).This scale determines high and low risk for presenting with an anxiety disorder by measuring four domains:- 1) Excessive Worry and Specific Fears; 2) Perfectionism, Control and Trauma; 3) Social Anxiety; 4) Acute Anxiety and Adjustment. Women with a PASS score of $\geq 26$ were considered to be at high risk of anxiety. Women who were found to have psychological distress or were at high risk for anxiety were referred to a specialist for further evaluation and management.

Data was entered in Microsoft Excel and analysed using SPSS version 16.Sociodemographic, obstetric and outcome variables (psychological distress and anxiety) were described by frequencies and proportions. Normality of the primary variables was checked by using ShapiroWilk test. The association of the outcome variables with various socio-demographic and obstetric variables was identified using
Chi-Square test. $\mathrm{P}$ value of $<0.05$ was considered to be statistically significant.

\section{Results and Discussion}

There were a total of 209 women who participated in this study. Mean age of the women was $22.4 \pm 2.5$ years, while mean age of their husbands was $29.04 \pm 3.5$ years. All the participants were married and majority were Hindu (93.8\%), educated till secondary school or higher $(98.5 \%)$ and were home makers (97.1\%). $191 \quad(91.4 \%)$ of the husbands had completed their secondary education or higher. Majority of the women lived in joint families and 101(48.3\%) belonged to class 3 socio-economic-status according to modified B G Prasad scale. 143 $(68.4 \%)$ of the study subjects were in the third trimester of pregnancy and $66(31.6 \%)$ were in second trimester, none were in the first trimester118 $(56.5 \%)$ participants were primigravida and39 (18.7\%) had bad obstetric histories including abortions and still births. None of the participants smoked or consumed alcohol, though $7(3.3 \%)$ reported alcohol consumption by the husband. In the present study, 62 women scored 16 or higher on K10. The prevalence of Psychological Stress among the antenatal women was therefore estimated to be $29.7 \%$, with prevalence rate of $26(39.4 \%)$ in second trimester being significantly higher than 36 (25.2\%)in the third trimester(See Table 1).Psychological distress was also significantly higher among women whose husband was educated upto Std 10 (35.4\%), as compared to those whose husband was educated beyond Std 10 (20.3\%).In this study, 64 women scored 26 or higher on PASS. Therefore $30.6 \%$ of the antenatal women were estimated to be at a high risk for anxiety. The proportion of women with a high risk for anxiety was significantly higher among women in the second trimester $(40.9 \%)$ as compared to those in the third trimester $(25.9 \%)$. 
Int.J.Curr.Res.Aca.Rev.2016; 4(4): 166-173

Table.1 Association of Psychological Distress and Anxiety with various socio-demographic and obstetric factors

\begin{tabular}{|c|c|c|c|c|c|}
\hline & $\begin{array}{l}\text { Total } \\
\mathrm{N}(\%)^{\text {a }}\end{array}$ & $\begin{array}{l}\text { K10 score } \geq 16 \\
\text { N }(\%)^{b}\end{array}$ & $\mathrm{P}$ value & $\begin{array}{l}\text { PASS score } \geq \\
26 \mathrm{~N}(\%)^{\mathrm{c}}\end{array}$ & $\mathrm{P}$ value \\
\hline \multicolumn{6}{|c|}{ Woman's age in completed years } \\
\hline$<20$ & $21(10.1)$ & $4(19.0)$ & \multirow{3}{*}{0.236} & $10(47.6)$ & \multirow[t]{3}{*}{0.176} \\
\hline $20-25$ & $163(78)$ & $53(32.5)$ & & $48(29.4)$ & \\
\hline$>25$ & $25(11.9)$ & $5(20)$ & & $6(24.0)$ & \\
\hline \multicolumn{6}{|c|}{ Woman's Education } \\
\hline Std 10 or lower & $99(47.4)$ & $32(32.3)$ & \multirow[t]{2}{*}{0.259} & $33(33.3)$ & \multirow[t]{2}{*}{0.454} \\
\hline Above Std 10 & $110(52.6)$ & $30(27.3)$ & & $31(28.2)$ & \\
\hline \multicolumn{6}{|l|}{ Type of family } \\
\hline Nuclear & $52(24.9)$ & $14(26.9)$ & \multirow[t]{2}{*}{0.62} & $13(25)$ & \multirow[t]{2}{*}{0.31} \\
\hline Joint & $157(75.1)$ & $48(30.6)$ & & $51(32.5)$ & \\
\hline \multicolumn{6}{|c|}{ Socioeconomic status by BG Prasad scale } \\
\hline Class 1 & $14(6.7)$ & $4(28.6)$ & \multirow{5}{*}{0.784} & $4(28.6)$ & \multirow{5}{*}{0.579} \\
\hline Class 2 & $45(21.5)$ & $14(31.1)$ & & $10(22.2)$ & \\
\hline Class 3 & $72(34.4)$ & $19(26.4)$ & & $23(31.9)$ & \\
\hline Class 4 & $67(32.1)$ & $20(29.9)$ & & $22(32.8)$ & \\
\hline Class 5 & $11(5.3)$ & $5(45.5)$ & & $5(45.5)$ & \\
\hline \multicolumn{6}{|c|}{ Husband's age in completed years } \\
\hline $20-25$ & $30(14.4)$ & $12(40.0)$ & \multirow{3}{*}{0.212} & $13(43.3)$ & \multirow[t]{3}{*}{0.236} \\
\hline $25-30$ & $136(65.1)$ & $35(25.7)$ & & $40(29.4)$ & \\
\hline$>30$ & $43(20.5)$ & $15(34.9)$ & & $11(25.6)$ & \\
\hline \multicolumn{6}{|c|}{ Husband's Education } \\
\hline Std 10 or lower & $130(62.2)$ & $46(35.4)$ & \multirow[t]{2}{*}{ 0.014* } & $44(33.8)$ & \multirow[t]{2}{*}{0.218} \\
\hline Above Std 10 & $79(37.8)$ & $16(20.3)$ & & $20(25.3)$ & \\
\hline \multicolumn{6}{|c|}{ Number of pregnancies } \\
\hline Primigravida & $118(56.5)$ & $36(35.0)$ & \multirow[t]{2}{*}{0.441} & $41(34.7)$ & \multirow[t]{2}{*}{0.173} \\
\hline Multigravida & $91(43.5)$ & $26(28.6)$ & & $23(25.3)$ & \\
\hline \multicolumn{6}{|c|}{ Trimester of pregnancy } \\
\hline Second trimester & $66(31.6)$ & $26(39.4)$ & \multirow[t]{2}{*}{ 0.028* } & $27(40.9)$ & \multirow[t]{2}{*}{$\mathbf{0 . 0 3 6}^{*}$} \\
\hline Third trimester & $143(68.4)$ & $36(25.2)$ & & $37(25.9)$ & \\
\hline \multicolumn{6}{|c|}{ Number of living children } \\
\hline 0 & $143(68.4)$ & $45(31.5)$ & & $51(35.7 \%)$ & \\
\hline 1 & $64(30.6)$ & $17(26.6)$ & 0.506 & $13(20.3)$ & 0.055 \\
\hline 2 or more & $2(1 \%)$ & $0(0)$ & & $0(0)$ & \\
\hline Number of fema & & & & & \\
\hline 0 & $169(80.9)$ & $54(32.0)$ & 0.095 & $56(33.1)$ & 0.128 \\
\hline 1 & $40(19.1)$ & $8(20.0)$ & & $8(20.0)$ & \\
\hline Previous Bad Ol & & & & & \\
\hline Yes & $40(19.1)$ & $13(32.5)$ & 0.398 & $15(37.5)$ & 0.294 \\
\hline No & $169(80.9)$ & $49(29.0)$ & & $49(29.0)$ & \\
\hline Reported alcoho & husband & & & & \\
\hline Yes & $7(3.3)$ & $4(57.1)$ & 0.118 & $5(71.4)$ & 0.029* \\
\hline No & $202(96.7)$ & $58(28.7)$ & & $59(29.2)$ & \\
\hline
\end{tabular}

*significant at $5 \%$ significance level; ${ }^{\text {a }}$ column percentage of individuals in each category compared to the total study subjects(209); ${ }^{\mathrm{b}}$ row percentage of individuals with K10 score $\geq 16$ in each category;

${ }^{c}$ row percentage of individuals with PASS score $\geq 26$ in each category 
High risk for anxiety was significantly greater among women whose husband consumed alcohol. The presence of either psychological distress or anxiety in the study population was not significantly associated with socio demographic factors like age of the subject, age of husband, education status of the subject, socioeconomic status, type of family, number of living children, presence of female children, and obstetric variables like parity index and previous bad obstetric history.

There was a significantly positive correlation between $\mathrm{K} 10$ and PASS scores with a correlation coefficient of 0.654 $(p=0.0001)$. This indicates that as psychological distress increases, the risk for anxiety also increases.

Depression and anxiety during pregnancy are known to have adverse maternal and neonatal outcomes. Psychological distress is indicative of symptoms of anxiety and depression. The present study sought understanding on the prevalence of psychological distress and anxiety using valid and reliable tools like K10 and PASS. The prevalence of psychological distress among antenatal women in the present study was estimatedto be $29.7 \%$.This is similar to the findings of a South African study (Peitzer K. et al., 2011)which estimated the prevalence of psychological distress among antenatal women to be $26.5 \%$, using the same instrument as the present study i.e., K10. In the present study, psychological distress was significantly associated with husband's education and early gestation, as compared to the South African study which found that unwanted pregnancy and presence of HIV and sexually transmitted disease were the main associated factors. Research in India thus far has not focused on psychological distress, but more on depression which is one of the underlying reasons for psychological distress. Hospital based studies in India conducted in urban Delhi (Shaily M. et al., 2012) and Bangalore City24(Bavle A.D. et al., 2012)found the prevalence of antenatal depression to be $17 \%$ and $12.3 \%$ respectively. A community based study done in rural Bangladesh (Nasreen et al., 2011)found that 18\% of antenatal women were depressed, while $24.5 \%$ was the prevalence of antenatal depression in the United States26(Hobfoll S.E. et al., 1995)

The prevalence of antenatal anxiety in the present study was found to be $30.6 \%$, which is slightly higher than the $22.6 \%$ prevalence of antenatal anxiety reported by a study in rural Bangalore27(Thomas C. Z. et al., 2015) using the same instrument i.e., PASS scale. The present study results are comparable toa study in urban New Delhi (Shaily M. et al., 2012) which reported the prevalence of antenatal anxiety to be $27 \%$., using Hospital Anxiety and Depression Scale. The studies done by Nasreen et al., in the rural Bangladesh (Nasreen et al., 2011) and by Giardinelli L. et al., in Italy (Giardinelli L. et al., 2012) also found comparable prevalences of $29 \%$ and $27.3 \%$ respectively. Antenatal anxiety in the present study, was found to be significantly associated with early gestation and alcohol consumption by the husband. The rural Bangalore study was associated with early gestation, increasing parity and previous history of abortion.

In the present study, though more than a quarter of the women suffered from psychological distress or anxiety, very few risk factors for these were found. Therefore, it is difficult to predict who are the women who are more likely to suffer from antenatal anxiety and psychological distress. This indicates that routine antenatal care must include screening for anxiety and 
psychological distress for all women. This study has important public health implications. It emphasizes the need for further investigation into psychological distress and anxiety during the antenatal period with the aim of improving maternal and neonatal outcomes. It also highlights the need for inquiry into possible preventive strategies and measures of intervention against depression and anxiety in the antenatal period which could be included in the antenatal health care package offered by primary health care workers to pregnant women.

\section{Conclusion}

Prevalence of Psychological distress and high risk for anxiety in rural antenatal women was found to be $29.7 \%$ and $30.6 \%$ respectively. Antenatal psychological distress and anxiety were significantly associated with alcohol consumption by the husband, education of the husband, and the period of gestation. The lack of predictive risk factors and high prevalence indicates a need for screening for psychological distress and anxiety during routine antenatal care for all women.

\section{References}

Austin, M., Hadzi-Pavlovic, D., Leader, L., Saint, K., Parker, G. 2005. Maternal trait anxiety, depression and life event stress in pregnancy: relationships with infant temperament. Early Human Development, 81(2): 183-190.

Bavle, A.D., Chandahalli, A.S., Phatak, A.S., Rangaiah, N., Kuthandahalli, S.M., Nagendra, P.N. 2016. Antenatal depression in a tertiary care hospital. Indian J. Psychol. Med., 38: 31-35.

Benute, G., Nomura, R., Reis, J., Fraguas Junior, R., Lucia, M., Zugaib, M. 2010. Depression during pregnancy in women with a medical disorder: risk factors and perinatal outcomes. Clinics, 65(11): 1127-1131. Fatoye, F.O., Adeyemi, A.B., Oladimeji, B. 2004. Emotional distress and its correlates among Nigerian women in late pregnancy. J. Obstetrics Gynecol., 24: 504-509.

Field, T., Diego, M., Hernandez-Reif, M. 2006. Prenatal depression effects on the fetus and newborn: a review. Infant Behavior and Development, 29(3): 445-455.

Giardinelli, L., Innocenti, A., Benni, L., Stefanini, M., Lino, G., Lunardi, C., Svelto, V., Afshar, S., Bovani, R., Castellini, G., Faravelli, C. 2011. Depression and anxiety in perinatal period: prevalence and risk factors in an Italian sample. Arch. Women's Mental Health, 15(1): 21-30.

Glover, V. 2002. Effects of antenatal stress and anxiety: Implications for development and psychiatry. The British J. Psychiatry, 180(5): 389-391.

Grande, E., Taylor, A., Wilson, D. 2002. South Australian Health and Wellbeing Survey, December 2000. Population Research and Outcome Studies Unit, Department of Health, South Australia.

Gulseren, L., Erol, A., Gulseren, S., Kuey, L., Kilic, B., Ergor, G. 2006. From antepartum to postpartum: a prospective study on the prevalence of peripartum depression in a semiurban Turkish community. J. Reproductive Med., 51: 955-960.

Heron, J., O'Connor, T.G., Evans, J., Glover, V. 2004. The course of anxiety and depression through pregnancy and the postpartum in a community sample. J. Affective Disorder, 80: 65-73.

Hobfoll, S., Ritter, C., Lavin, J., Hulsizer, M., Cameron, R. 1995. Depression 
Int.J.Curr.Res.Aca.Rev.2016; 4(4): 166-173

prevalence and incidence among inner-city pregnant and postpartum women.J. Consulting and Clin. Psychol., 63(3): 445-453.

Huizink, A., Mulder, E., Robles de Medina, P., Visser, G., Buitelaar, J. 2004. Is pregnancy anxiety a distinctive syndrome? Early Human Development, 79(2): 81-91.

K10 Symptom Scale. 2000. Clinical Research Unit for Anxiety and Depression. A WHO Collaborating Center. School of Psychiatry, University of NSW. [Online] Available at: http://www.crufad.unsw.edu.au/K10/k 10info.htm [Accessed on: 30/3/2015]

Kessler, R.C. 2004. Kessler Psychological Distress Scale (K10) - Statistics Solutions. [online] Statistics Solutions. Available at: https://www.statisticssolutions.com/ke ssler-psychological-distress-scalek10/ [Accessed 1 Jan. 2016].

Kessler, R.C., Barker, P.R., Colpe, L.J., Epstein, J.F., Gfroerer, J.C., Hiripi, E., Howes, M.J, Normand, S-L.T., Manderscheid, R.W., Walters, E.E., Zaslavsky, A.M. 2003. Screening for serious mental illness in the general population. Arch. General Psychiatry, 60(2): 184-189.

Marcus, S., Heringhausen, J. 2009. Depression in Childbearing Women: When Depression Complicates Pregnancy. Primary Care: Clin. Office Practice, 36(1): 151-165.

Mirowsky, J., Ross, C.E. 2002. Selecting outcomes for the sociology of mental health: Issues of measurement and dimensionality. J. Health and Social Behavior, 43: 152-170.

Nasreen, H., Kabir, Z., Forsell, Y., Edhborg, M. 2011. Prevalence and associated factors of depressive and anxiety symptoms during pregnancy: A population based study in rural Bangladesh. BMC Women's Health, 11(1): 22.

Nulman, I., Rovet, J., Stewart, D., Wolpin, J., Pace-Asciak, P., Shuhaiber, S., Koren, G. 2002. Child Development Following Exposure to Tricyclic Antidepressants or Fluoxetine Throughout Fetal Life: A Prospective, Controlled Study. American J. Psychiatry, 159(11): 1889-1895.

Patel, V., Rahman, A., Jacob, K.S., Hughes, M. 2004. Effect of maternal mental health on infant growth in low income countries: new evidence from South Asia. British J. Med., 328: 820-823.

Peitzer, K., Shikwane, E., Matseke, G. 2011. Psychological Distress and Associated Factors among a Sample of Pregnant Women in South Africa. J. Psychol., in Africa, 21(3): 495-499.

Rahman, A., Iqbal, Z., Bunn, J., Lovel, H., Harrington, R. 2004. Impact of Maternal Depression on Infant Nutritional Status and Illness. Arch. Gen. Psychiatry, 61(9): 946.

Shaily, M., Balhara, Y., Verma, R., Mathur, S. 2012. Anxiety and Depression amongst the urban females of Delhi in Ante-partum and Post-partum period. Delhi Psychiatry J., 15(2): 347-351.

Somerville, S., Dedman, K., Hagan, R., Oxnam, E., Wettinger, M., Byrne, S., Coo, S., Doherty, D., Page, A. 2014. The Perinatal Anxiety Screening Scale: development and preliminary validation. Arch. Women's Mental Health, 17(5): 443-454.

Srinath, S., Girimaji, S.C., Gururaj, G., Seshadri, S., Subbakrishna, D.K., Bhola, P., Kumar, N. 2005. Epidemiological study of child \& adolescent psychiatric disorders in urban \& rural areas of Bangalore, India.Indian J. Med. Res., 122(1): 6779. 
Stewart, R. 2007. Maternal depression and infant growth: a review of recent evidence. Maternal and Child Nutrition, 3(2): 94-107.

Teixeira, C., Figueiredo, B., Conde, A., Pacheco, A., Costa, R. 2009. Anxiety and depression during pregnancy in women and men. $J$. Affective Disorders, 119: 142-8.

Thomas, C.Z., A.S., A.S., Puthur, K.J., Kiran, P., T.S. 2015. Screening for Anxiety among Antenatal Women Attending a Taluk Hospital in Rural India. National J. Community Med., 6(3): 313-317.

\section{How to cite this article:}

Avita Rose Johnson, Sineesh P Joy, Niresh Chandran, Rajitha K, Nishma Monteiro, Linju Varghese, Vinoliya Sudha and Twinkle Agrawal. 2016. Psychological Distress and Risk of Anxiety among Women Availing Antenatal Services at a Hospital in Rural South India. Int.J.Curr.Res.Aca.Rev.4(4): 166-173. doi: http://dx.doi.org/10.20546/ijcrar.2016.404.020 